ИЗВЕСТИЯ АҚАДЕМИИ НАУК ЭСТОНСКОИ ССР. ТОМ 29 ГЕОЛОГИЯ. 1980, Ni 4

\title{
ХИТИНОЗОИ СРЕДНЕГО ЛЛАНДОВЕРИ ЭСТОНИИ
}

Среднему лландовери в Әстонии соответствуют породы верхней половины райккюлаского горизонта. В привыходном районе отложения этого возраста или отсутствуют, или, возможно, частью представлены зернистыми и коралловыми известняками кулламааской свиты, не содержащими хитинозой (Нестор, 1976). Разрез саардеской свиты (см. Аалоэ и др., 1976) вскрыт только буровыми скважинами и он наиболее полный и мощный в Юго-Западной Эстонии (Кальо, 1970). В этом районе породы рассматриваемого интервала (иклаская, леммеская и стайцельская пачки) представлены преимущественно мергелями, афанитовыми и глинистыми известняками, в которых везикулы хитинозой в подавляющем большинстве сильно сплюснуты. При таком материале многие таксономические признаки неузнаваемы. В данной статье не описываются некоторые виды, встречающиеся немногочисленными экземплярами неудовлетворительной сохранности, в частности некоторые конохитины, а также Ancyrochitina ancyrea и A. cf. primitiva.

Распространение рассматриваемых видов в разрезах ряда буровых скважин изложено ранее (Нестор, 1976). Новые данные о распространении в разрезах скважин Хяэдэмеэсте и Лаэва хорошо сходятся с предыдущими.

Верхняя граница среднего лландовери принята согласно Р. Эйнасто и др. (1972), нижняя - дискутировалась в связи с описанием новых видов нижне-лландоверийских хитинозой Эстонии (Нестор, 1980). Данная работа является непосредственным продолжением вышеотмеченной.

Автор признателен Р. Мяннилю и Х. Нестору за полезные советы при редактировании рукописи и Д. Марк за помощь при обработке проб. Микрофотографии выполнены на сканирующем электронном микроскопе фирмы «Акаси» Е. Климовым и М. Аннивал. Материал хранится в Институте геологии АН ЭССР.

\section{ТАБЛИЦА I}

Фиг. 1-2. Ancyrochitina convexa sp. n. $\mathrm{G}_{3} .1$ - голотип Ch 14/1810, скв. Рухну, гл. 536,0 м, 1а - вид с боку, $\times 460,16-$ деталь, $\times 660 ; 2-$ экз. Сh $15 / 1810$, скв. Рухну, гл. 536,0 м, $2 a-$ вид с боку, $\times 250,26-$ деталь, $\times 660,2 \varepsilon-$ деталь, $\times 1360$.

\section{ТАБЛИЦА II}

Фиг. 1-2. Coronochitina maennili sp. п. G. 1 - голотип Ch $2 / 1462$, скв. Икла, гл. 462,9 м, 1а - вид с боку, Х250, $16-$ - деталь, Х1360; 2 - экз. Сh $1 / 1686$, скв. Рухну, гл. 573,3 м, $2 a-$ вид с боку, $\times 250,26$ - деталь, $\times 1360$. 
ТАБЛИЦА I
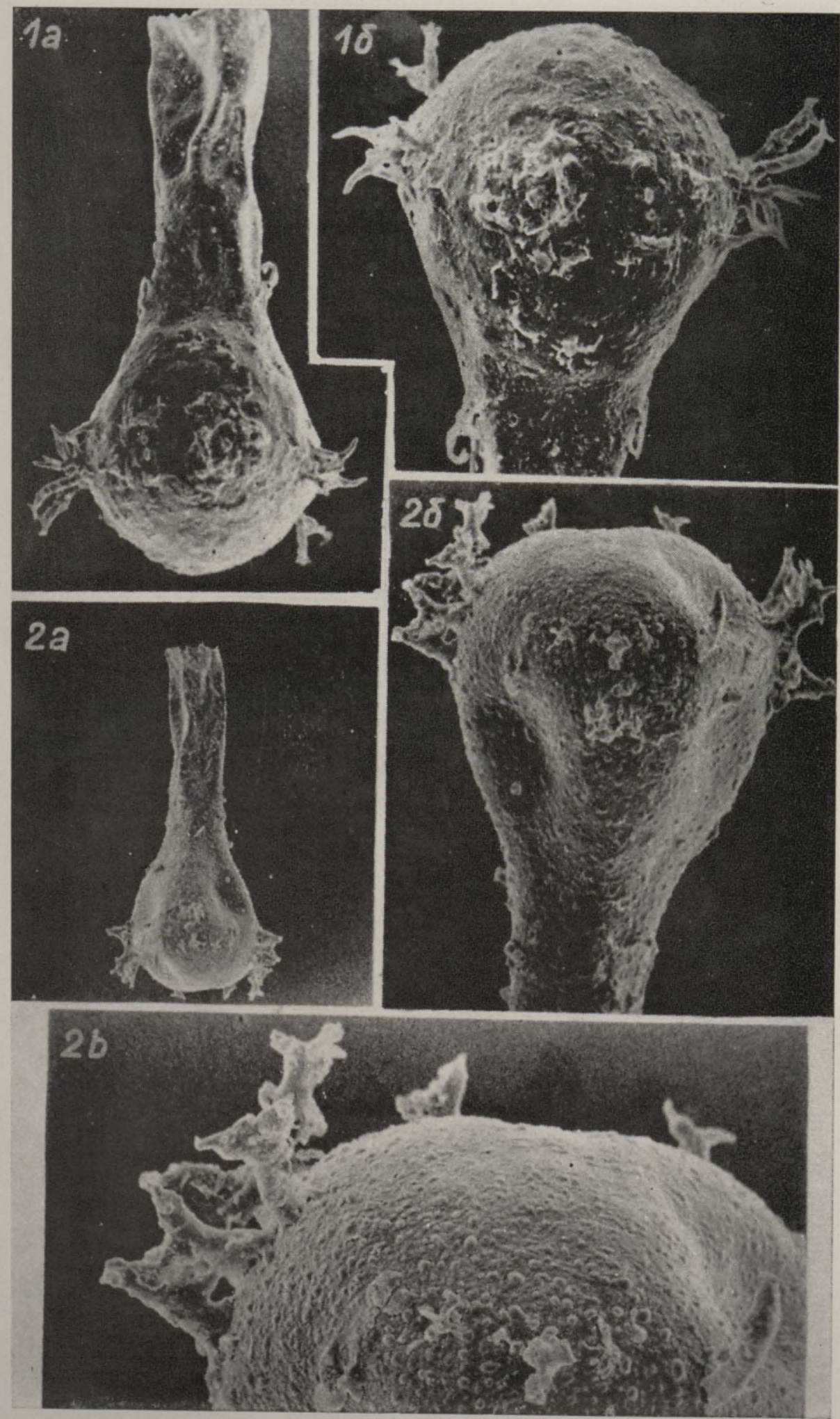


\section{ТАБЛИЦА II}
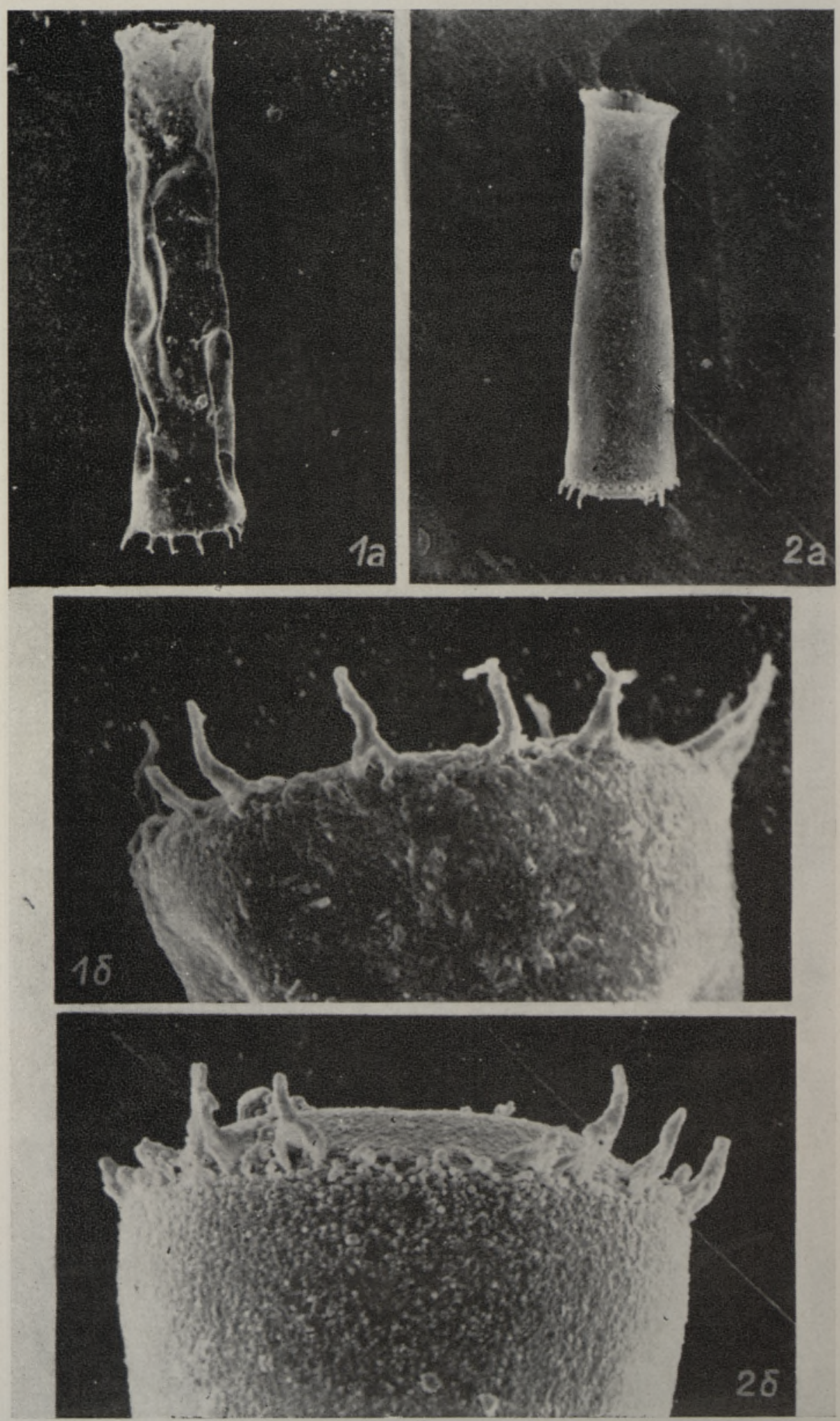

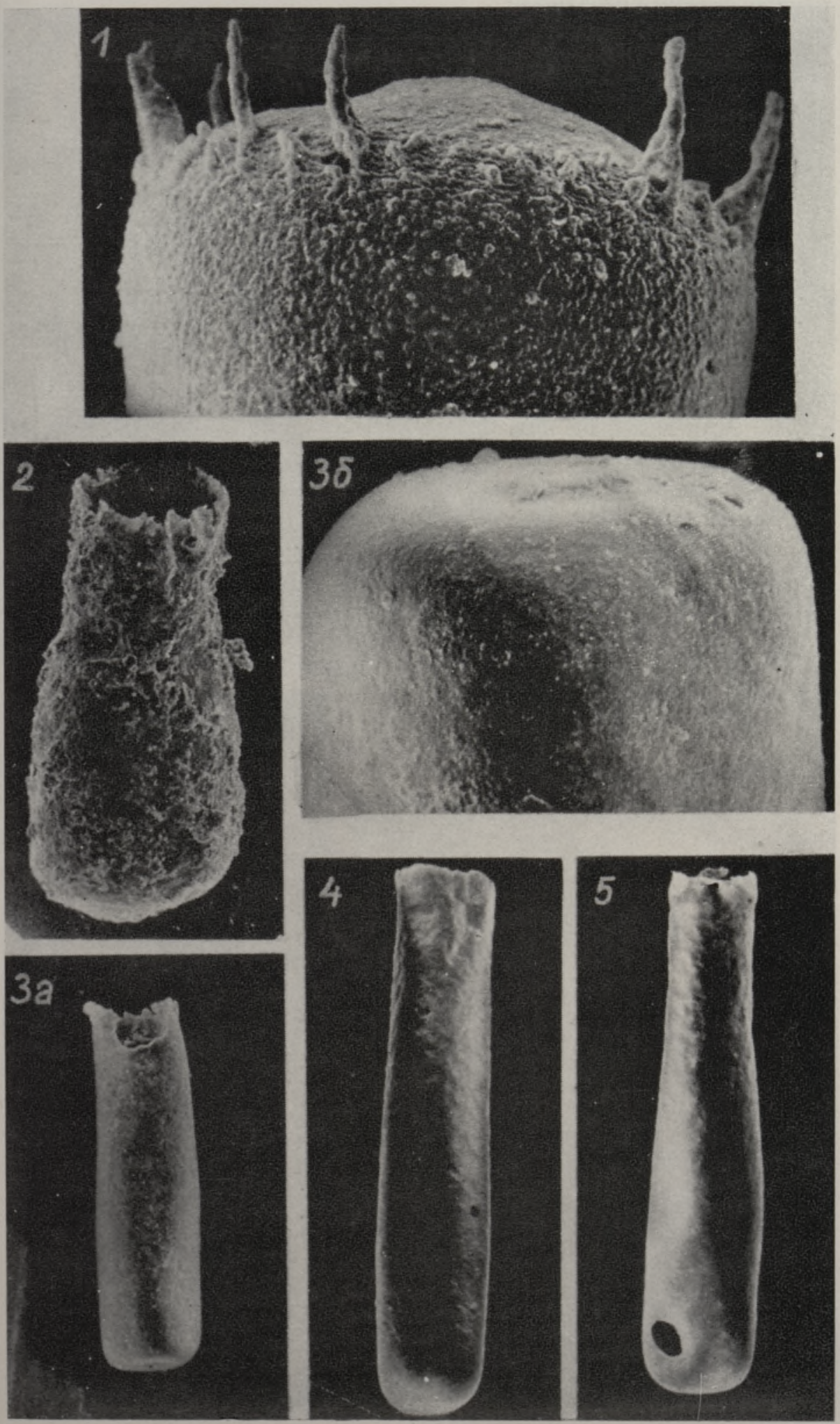

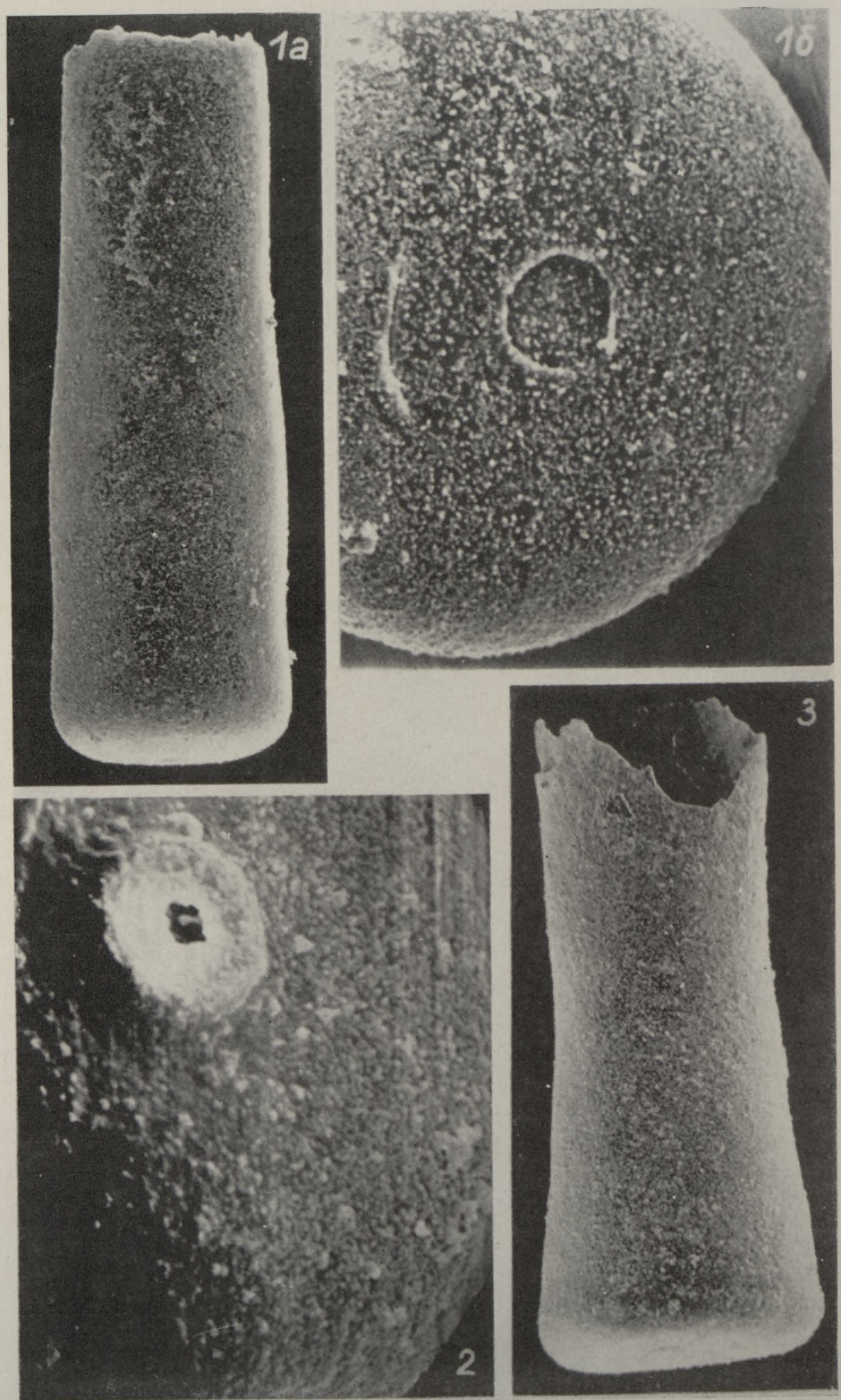


\section{Род Ancyrochitina Eisenack, 1955}

Ancyrochitina convexa sp. n.

Табл. I, фиг. $1-2$

Ancyrochitina cf. tomentosa - Нестор, 1976, c. 321. Ancochitina sp. - Нестор, 1976, с. 321.

\section{Н а з ван и е вид а от convexa (лат.) - выпуклый.}

Голоти п: Ch 14/1810, скв. Рухну, гл. 536 м, райккюлаский горизонт. Ди а гноз. Везикула цилиндро-коническая до цилиндро-сферической, с выпуклым основанием и широко закругленным базальным краем. Короткие согнутые отростки, расположенные обычно 6-8 группами, увенчивают базальный край. Отростки простые или разветвляются до 3-4 раз. Проксимальная, неразветвляющаяся часть отростка составляет меньше половины его общей длины. На флексуре и нижней части шейки прикреплены сильно согнутые мелкие шипики.

$\mathrm{O}$ п и с а н и. Шейка составляет обычно больше половины длины везикулы. Основание часто сильно выпуклое, так что камера обладает почти сферической формой без четкого базального края. Цилиндрическая шейка немного расширяется в сторону мелкобахромчатого устья. Заметная флексура и широко закругленные плечи имеются у большинства экземпляров. Короткие базальные отростки обычно сгруппированы беспорядочно по 2-5 отростков, расположенных в полосе округленного базального края. Длина отростков равна примерно $1 / 3$ диаметра камеры. Разветвление отростков сложное. Иногда это происходит веерообразно, иногда отростки соединены друг с другом перемычками. Отростки сами неправильные, неравномерной толщины, полые. Полость не имеет соединения с внутренностью везикулы. Сильно согунтые шипики в. окрестности флексуры очень хрупкие и поэтому они обычно ломанные. Верхняя поверхность везикулы мелкогранулированная.

Р а з ме ры (микроны): длина везикулы 150-215 (голотипа 185), ширина (вместе с отростками) 105-145 (голотипа 120), максимальная длина отростков 30 (голотипа 25).

С равнение и замечания. Отличается от $A$. tomentosa (Taugourdeau, Jekhowsky, 1960) формой основания и характером орнаментации поверхности везикулы. От A. laevaensis (Нестор, 1980) отличается

\section{ТАБЛИЦА III}

Фиг. 1. Coronochitina maennili sp. п., базальная часть экземпляра Ch $3 / 1686$, скв. Рухну, гл. 573,3 $\mu, \mathrm{G}_{3}, \times 1360$. Фиг. 2. Conochitina edjelensis edjelensis Taugourdeau, $\mathrm{G}_{3}$, экз. Ch 32/1926, вид с боку, скв. Варбла, гл. 176,05 м, Х460. Фиг. 3-5. Conochitina iklaensis sp. n. G. 3 - экз. Ch 40/1682, скв. Рухну, гл. 584,0 м, $3 a-$ вид с боку, $\times 250,36$ - основание с низким мукроном, $\times 1360 ; 4-$ экз. Ch $39 / 1445$, скв. Икла, гл. 492,0 м, $\times 250 ; 5$ - голотип Ch $38 / 1445$, скв. Икла, гл. 492,0 м, $\times 250$.

\section{ТАБЛИЦА IV}

Фиг. 1-2. Conochitina edjelensis alargada Cramer, скв. Варбла, гл. 173,4 м, G $3.1-$ экз. Ch $34 / 1378,1 a-$ вид с боку, $\times 460,16$ - основание с базальным скаром, $\times 1360$; 2 - экз. Ch $35 / 1378$, деталь основания с низким мукроном, $\times 200$. Фиг. 3. Conochitina edjelensis elongata Taugourdeau, экз. 'С $33 / 1378$, вид с боку; скв. Варбла, гл. 173,4 м, $\times 460$. 
более выпуклым основанием, формой отростков и наличием шипиков на шейке.

Отростки $A$. convexa хрупкие и легко. ломаются. Экземпляры, у которых отростки не сохранились, можно (особенно при сплюснутом материале) ошибочно отнести к роду Angochitina (см. Angochitina sp. в работе Нестор, $1976=$ Ancyrochitina convexa).

Распространение и м тери ал. Распространение $A$. convexa в некоторых разрезах райккюлаского горизонта среднего лландовери Эстонии описано ранее автором в 1976 г. (под названием A. cf. tomentosa). Встречается в верхах колкской и в иклаской пачке в скв. Икла, гл. 441-467 м; скв. Охесааре, гл. 373-384 м; скв. Рухну, гл. 535560 м; скв. Варбла, гл. 182-185 м; скв. Хяэдемеэсте, гл. 274-314 м.

По данным изучения скв. Икла (Кальо, Вингисаар, 1969) и Охесааре (Кальо, 1967) интервал распространения $A$. convexa грубо совпадает с нижней частью граптолитовой зоны Coronograptus gregarius. Материал - более 100 экземпляров.

\section{Род Coronochitina Eisenack, 1965}

Coronochitina maennili sp. $\mathrm{n}$.

Табл. II, фиг. $1-2$; табл. III, фиг. 1

Coronochitina sp. - Мянниль, 1970 , с. 178.

Coronochitina sp. n. - Нестор, 1976, с. 322.

В и д на з в а н в честь д-ра Р. Мянниля, который первым отметил присутствие данного вида в силуре Әстонии (Мянниль, 1970).

Голоти п: Ch 4/1462, скв. Икла, гл. 462,9 м, райккюлаский горизонт.

Диагноз. Везикула субконическая до субцилиндрической. Более узкая субцилиндрическая шейка переходит плавно в камеру. Базальный край снабжен короной простых или разветвляющихся тонких шипов, расширяющихся в сторону основания, где они обычно разделяются или имеют открытую стенку. Поверхность везикулы мелкозернистая.

О пи с ан ие. Камера имеет максимальную ширину у базального края. Длина шейки изменчива, она составляет примерно $1 / 3-1 / 2$ всей длины везикулы. Иногда переход шейки в камеру постепенный, так что их трудно разграничить. Непосредственно перед устьем шейка немного расширяется. Устье неровное - тонко-бахромчатое. В базальной части камеры иногда имеется небольшое расширение. Базальный край слабо округленный, снабженный короной неравномерно-тонких сравнительно длинных шипов, расположенных в плоскости боковой стенки и обычно легко изогнутых в направлении середины основания. Расширенное основание шипов часто двух- или многокорневое или подкововидное с открытой стенкой. С внутренностью везикулы шипы соединения не имеют. Количество шипов варьирует от 8 до 20, но обычно их $10-15$. При сплюснутом материале большинство или все шипы разломаны.

Основание везикулы обычно вогнутое или плоское, реже слабовыпуклое. Внешняя поверхность везикулы мелкозернистая, зерна более крупные в полосе базального края.

Р азмеры (микроны): длина везикулы (включая шипы) 160-450 (голотипа 340), максимальная ширина $45-110$ (голотипа 70), минимальная ширина 30-80 (голотипа 55), максимальная длина шипов 15 . 
С равнение и 3 а ме ч ан ия. От ордовикского вида Coronochitina coronata (Eisenack, 1931) C. maennili отличается отсутствием широкого воронкообразного вздутия в базальной части камеры, а также гранулированной поверхностью везикулы. Кроме того, на устьевом краю у описанного вида шипы не встречены и строение базальных шипов отличается - у C. coronata шипы простые. C. fragilis (Нестор, 1980) отличается простыми, более короткими и хрупкими шипиками, более конической формой и гладкой поверхностью везикулы.

Р аспространение и м а тери ал. Coronochitina maennili - характерный вид для среднего лландовери Прибалтики, вероятно, связан с более глубоководными отложениями (= Coronochitina sp. n., Нестор, 1976). Встречается во всех изученных разрезах райккюлаского горизонта Юго-Западной Эстонии - скв. Икла, в колкской, иклаской и нижней половине леммеской пачки, гл. 386-475 м; скв. Рухну, гл. 494-574 м; скв. Охесааре, гл. 373-397 $м$; скв. Хяэдемеэсте, гл. $274-$ 367 м. По данным из скв. Икла (см. Кальо, Вингисаар, 1969) более многочисленно вид представлен в пределах граптолитовой зоны Coronograptus gregarius.

Материал - более тысячи экземпляров.

Род Conochitina Eisenack, 1931

Conochitina iklaensis sp. $\mathrm{n}$.

Табл. III, фиг. 3-5

Н аз ван ие в ид а от названия скв. Икла, из керна которой происходит голотип.

Г олоти п: Ch 38/1445, скв. Икла, гл. 492,0 м, райккюлаский горизонт. Ди агноз. Везикула субцилиндрическая с широко округленным базальным краем. Основание плоское или слабо вогнутое, с базальным скаром в центре.

Опи и ание. Стенки везикулы обычно прямые, почти параллельные, иногда слабо выпуклые. Флексура отсутствует или едва заметная. Несколько выше базального края иногда отмечается слабое сжимание стенок везикулы. Отношение длины к ширине в среднем $4: 1-6: 1$. Видовые признаки слабо развиты и зачастую скрыты при деформации материала.

Внешняя поверхность везикулы гладкая.

Р а з м еры (микроны): длина везикулы 220-580 (голотипа 320), максимальная ширина $45-70$ (голотипа 60), ширина устья $40-60$ (голотипа 50).

С равнение и 3 а ме ч а и я. Сплюснутые экземпляры нашего материала на первый взгляд сходны с некоторыми нижне- и среднеордовикскими видами Южной Европы (см. Taugourdeau, 1961; Jenkins, 1967), но из-за деформации материала трудно провести надежную идентификацию, тем более что возрастное различие названных форм слишком большое.

Эстонский материал этого вида похож и на средне-сибирский материал, полученный из реки Горбиячин и описанный Н. М. Заславской (в печати), но до проведения непосредственного сравнения материалов невозможно установить идентичность с ним, тем более, что C. iklaensis обладает признаками нескольких видов, выделенных Н. М. Заславской. 
Р аспространение этого вида переходит границы среднего лландовери: он встречается и в верхах нижнего и в самых низах верхнего лландовери, по данным из скв. Икла в основном от граптолитовой зоны Coronograptus cyphus до Demirastrites convolutus включительно: скв. Икла, гл. 311-504 $м$; скв. Охесааре, гл. 373-409 м; скв. Рухну, гл. 484-588 м; скв. Варбла, гл. 160-219 м; скв. Хяэдемеэсте, гл. 222389 м; скв. Лаэва, гл. 54-93 м; скв. Кирикукюла, гл. 83-87 ; скв. Азукюла, гл. 13-18 м; скв. Сулуствере, гл. $71-77$ м. Следует отметить, что в разрезах последних трех привыходных скважин данный вид присутствует только в низах горизонта, где развиты относительно глубоководные отложения (т. н. валастеские мергели), что указывает на вероятную фациальную зависимость его распространения.

$M$ а тер и ал. Более тысячи экземпляров.

\section{Conochitina edjelensis Taugourdeau}

Табл. III, фиг. 2; табл. IV, фиг. 1-3

Conochitina cf. edjelensis - Нестор, 1976, с. 322.

3 а ме чания. Conochitina edjelensis и его подвид $C$. edjelensis elongata впервые описаны Р. Тогурдо (Тaugourdeau, 1963) из слоев среднего и верхнего лландовери Сахары. По встречаемости эти подвиды там «частые» или «очень частые». Позднее Ф. Kремер (Cramer, 1967) в добавление к этим описал еще подвид alargada из лландоверийских слоев Северной Испании, но рассматривает все эти три подвида в едином комплексе, так как они встречаются совместно, их стратиграфический интервал распространения совпадает и из-за изменчивости подвиды сами трудно различимы друг от друга.

В средне-лландоверийских слоях Прибалтики встречается близкий к тому комплекс форм, различаемый главным образом по более крупным размерам. Әстонский материал характеризуется также сильной изменчивостью форм и совместным присутствием разных подвидов в разрезе. Все подвиды обладают широкой шейкой и широким устьем. Внешняя поверхность везикулы гладкая до неравномерно-зернистой (зернистость, возможно, секундарная). Средняя длина экземпляров в типовой коллекции (по Тaugourdeau, 1963, табл. 2, с. 132) 150-250 микронов, у прибалтийских 250-350. Следует отметить, что при сравнении хитинозой силура Сахары и о. Готланд П. Тогурдо и П. Еховский (Taugourdeau, Jekhowsky, 1964) обратили внимание на более многочисленное распространение и более крупные размеры конохитин в Прибалтийском регионе.

C. edelensis edjelensis - сравнительно редкая форма в разрезе Эстонии, присутствующая единичными экземплярами, размерами не меньше 200 микронов (у голотипа 150). Отношение длины везикулы к ширине остается близким к этому отношению у типового материала (табл. III, фиг. 2).

Камера C. edjelensis elongata имеет тенденцию расширяться к базальному краю. Основание обычно плоское или слабо вогнутое. Ширококонический экземпляр, изображенный в данной работе (табл. IV, фиг. 3), для этого вида крайностный.

Представители $C$. edjelensis alargada аналогично типовому экземпляру (Cramer, 1967, табл. III, фиг. 55), характеризуются слабой выпуклостью камеры и по сравнению с другими подвидами - более.крупной формой везикулы. (табл. IV, фиг. 1a). Основание обычно плоское 
с базальным скаром в центре (табл. IV, фиг. 1б). Иногда присутствует низкий мукрон. (табл. VI, фиг. 2).

Р а сп ростр ан ени е. Встречается: скв. Икла, гл. $318-471$ м; скв. Рухну, гл. 490-556 $м$; скв. Охесааре, гл. 373-381 $м$; скв. Вар5ла, гл. 163-192 м; скв. Хяэдемеэсте, гл. 232-235 м. По данным изучения скв. Икла (см. Кальо, Вингисаар, 1969) распространяется в пределах граптолитовых зон Coronograptus gregarius и Monograptus convolutus. Материал - более тысячи экземпляров.

\section{ЛИТЕРАТ У Р А}

Аалоэ А., Кальо Д., Клааманн Э., Нестор Х., Эйнасто Р. Стратиграфическая схема силура Эстонии. - Изв. АН ЭССР. Хим. Геол., 1976, 25, $38-45$.

Кальо Д. Л. О возрасте нижних горизонтов силура Эстонии. - Изв. АН ЭССР, Хим. Геол., $1967,16,62-68$.

Каль о Д. Л. Райккюлаский горизонт. - В кн.: Силур Эстонии (Ред. Кальо Д. Л.). Таллин, 1970, 221-232.

К альо Д., Винги са ар П. О разрезе райккюлаского горизонта на южной окраине Эстонии. - Изв. АН ЭССР. Хим. Геол., 1969, 18, 270-277.

М я н н и ль Р. М. Кислотоустойчивые микрофоссилии. - В кн.: Силур Эстонии (Ред. Кальо Д. Л.). Таллин, $1970,176-179$.

Не стор В. Сопоставление некоторых разрезов райккюлаского горизонта Эстонии по микропланктону. - Изв. АН ЭССР. Хим. Геол., 1976, 25, 319-324.

Несто о В. Новые виды хитинозой из нижнего лландовери Эстонии. - Изв. АН ЭССР. Геол., 1980, 29, 98-106.

Эй н а с т о Р., Н ес т о р Х., К а л а Э., К а я к К. Сопоставление верхнелландоверийских разрезов в Западной Эстонии. - Изв. АН ЭССР. Хим. Геол., 1972, 21, 333-343.

Cramer, F. H. Chitinozoans of a composite section of Upper Llandoverian to basal Gedinnian sediments in northern Leon, Spain. A preliminary report. - Bull. Soc. Belg. Geol. 11967, 75, 69-129.

E is en a ck, A. Die Mikrofauna der Ostseekalke. - N. Jb. Geol. Paläont. Abh., 1965, 2, $115-148$.

Jenkins, W. A. M. Ordovician Chitinozoa from Shropshire. - Palaeontology 1967, $10,436-488$

T a ug ourdeau, P. Chitinozoaires du Silurien d'Aquitaine. - Rev. Micropaléont. $1961,4,135-154$.

T a u g o urdeau, P. Etude de quelques espèces critiques de Chitinozoaires de la region d'Edjèle. - Rev. Micropaléont., 1963, 6, 130-144.

T a u g ourdeau, P., De Jekhowsky, P. Répartition et description des chitinozoaires Siluro-Devoniens de quelques sondages de la C. R. E. P. S., de la C. F. P. A. et de la S. N. au Sahara. - Rev. Inst. Franc. Pétrole Ann. Combust. Liquides, $11960,15,1199-1260$.

T a u gourdeau, P., De Jekhowsky, P. Chitinozoaires Siluriens de Gotland; Comparaison avec les formes sahariennes. - Rev. Inst. Franc. Pétrole Ann. Combust. Liquides, 1964, 19, 845-871.

Ннститут геологии

Академии наук Эстонской ССР
Поступила в редакцию 14/III 1980

Viiu NESTOR

\section{EESTI KESKLÄNDOUVERI KITINOZOAD}

Artiklis on esitatud nelja kitinozoaliigi kirjeldus ja levik raikküla lademes. Kolme neist on käsitletud uute liikidena. 
Viiu NESTOR

\section{MIDDLE LLANDOVERIAN CHITINOZOANS FROM ESTONIA}

In the Estonian sequence, Middle Llandoverian beds are distinguished only in the south-western borings where they are represented by micritic (aphanitic) limestones, marls and mudstones of the upper part of the Raikküla Stage (Ikla, Lemme and Staitsele members of the Saarde Formation - see Aaloe et al., 1976). The chitinozoans described in this paper come entirely from this area. In the Central Estonian outcrop area synchronous beds are either lacking or represented only by some parts of the Kullamaa Formation that does not contain chitinozoans (Nestor, 1976). The present paper serves as a continuation of an earlier one by the author (Nestor, 1980). Distribution of the species described has been discussed earlier (Nestor, 1976).

\section{Ancyrochitina convexa sp. $\mathrm{n}$.}

Cylindro-conical to sphaerical vesicle with highly convex base and broadly rounded basal edge. Short curved appendices, less than a half of the chamber diameter in length, are placed irregularly in $6-8$ groups along the basal edge. In a group there are usually $2-5$ appendices, simple or branching up to $3-4$ times. The pattern of branching is complicated, occasionally small cross-bars join two appendices within the group. The finest spines are attached to the lower part of the neck just oralward of the flexure. The vesicle wall is finely granulated.

\section{Conochitina maennili sp. $\mathrm{n}$.}

Subcylindrical to elongated-conical vesicle with bluntly rounded basal edge, provided with a crown of smatl simple spines, occasionally branching $1-2$ times. Most spines commonly divide also in the proximal part, forming a two- or multi-rooted base, or have walls that are not entirely closed. The number of spines is variable $-8-20$ (commonly $10-15$ ). The base is concave or flat, rarely slightly convex. The flanks of the vesicle are occasionally somewhat constricted oralward of the basal edge and widened at the finely fringed aperture. The vesicle wall is usually covered by fine granules.

\section{Conochitina iklaensis sp. 'n.}

Subcylindrical vesicle with broadly rounded basal edge. The base is flat or slightly concave, with basal scar in the centre of a sunken area. The flanks of the vesicle are straight or slightly swollen. Occasionally the flanks are somewhat constricted oralward of the basal edge. Maximum diameter is generally $1 / 6$ to $1 / 4$ of total length. The vesicle wall is smooth.

\section{Conochitina edjelensis Taugourdeau}

Subcylindrical and subconical vesicles show great morphological variation, but in general are similar to the type material described from Sahara (Taugourdeau, 1963) and Spain (Cramer, 1967). The main difference of the Estonian material consists in the large dimensions of the vesicles, while the length-width relation remains the same. Three subspecies are distinguishable, although not throughout the sequence. This depends on the state of preservation of the material: where it is bad, subspecies are not separable. They occur together and have the same stratigraphical range which is closely similar to that of the type material. 